\title{
Association between SOX9 and CA9 in glioma, and its effects on chemosensitivity to TMZ
}

\author{
XIAOSHAN XU ${ }^{1 *}$, ZHEN WANG $^{1 *}$, NAN LIU ${ }^{1}$, YINGDUAN CHENG ${ }^{1,2}$, WEILIN JIN ${ }^{3}$, PENGXING ZHANG $^{1}$,

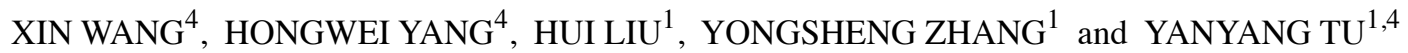 \\ ${ }^{1}$ Department of Experimental Surgery, Tangdu Hospital, Fourth Military Medical University, Xi'an, \\ Shaanxi 710038, P.R. China; ${ }^{2}$ Department of Research, Cipher Ground, North Brunswick, NJ 08902, USA; \\ ${ }^{3}$ Key Laboratory for Thin Film and Microfabrication Technology of the Ministry of Education, \\ Institute of Nano Biomedicine and Engineering, Department of Instrument Science and Engineering, \\ School of Electronic Information and Electronic Engineering, Shanghai Jiao Tong University, \\ Shanghai 200240, P.R. China; ${ }^{4}$ Department of Neurosurgery, Brigham and Women's Hospital, \\ Harvard Medical School, Boston, MA 02115, USA
}

Received September 4, 2017; Accepted April 4, 2018

DOI: $10.3892 /$ ijo.2018.4382

\begin{abstract}
Temozolomide (TMZ) is a standard chemotherapeutic drug used in the treatment of glioblastoma multiforme (GBM); however, resistance to this drug is common. SRY-Box 9 (SOX9) expression is associated with a poor prognosis of patients with GBM and with resistance to TMZ. Therefore, the aim of this study was to examine the effects of SOX9 inhibition on the sensitivity of glioma cells to TMZ treatment. We knocked down the expression of SOX9 (SOX9KD) via lentiviral infection in two glioblastoma (U87 and U251) cell lines, and the cells were then subjected to gene microarray, Gene Ontology and KEGG analysis pathway, all of which revealed a close association between SOX 9 and the carbonic anhydrase 9 (CA9) gene. The TMZ-mediated apoptosis of glioma cells was significantly increased in the cells in the SOX9KD group. The potential underlying mechanism involved the downregulation of SOX9 and CA9 expression, which in turn decreased Akt phosphorylation, downregulated BCL-2 expression, and upregulated BAX expression, as assessed by western blot analysis and RT-qPCR. The effects were found to be substantially enhanced in the cells in the SOX9KD group treated with TMZ. Subsequently, considering the association between SOX9 and CA9, the effects of CA9 inhibition, using a CA9 inhibitor
\end{abstract}

Correspondence to: Professor Yongsheng Zhang or Dr Yanyang Tu, Department of Experimental Surgery, Tangdu Hospital, Fourth Military Medical University, 569 Xinsi Road, Xi'an, Shaanxi 710038, P.R. China

E-mail: zhang_yongsheng@163.com

E-mail: ayonst@163.com

${ }^{*}$ Contributed equally

Key words: SOX9, CA9, glioma, chemosensitivity to temozolomide, combination therapy
(U-104), on the chemosensitivity of glioma cells to TMZ were assessed. The results revealed that the use of U-104 + TMZ effectively induced glioma cell death, compared to treatment with TMZ alone. The underlying mechanisms were similar to those observed with the silencing of SOX9 in the TMZ-treated glioma cells. On the whole, the findings of this study establish the SOX9/CA9-mediated oncogenic pathway in glioma, the inhibition of which enhances the sensitivity of glioma cells to TMZ treatment, and thus highlights the value of developing small molecules or antibodies against the SOX9/CA9 pathway, for combination therapy with $\mathrm{TMZ}$, in the more efficient management of glioma.

\section{Introduction}

Glioma is one of the most common primary malignancies of the central nervous system (CNS), accounting for approximately $40 \%$ of all intracranial tumors (1). According to the WHO glioma grading criteria, gliomas are divided into low-grade (I and II) and high-grade (III and IV) gliomas (2). High-grade gliomas, including anaplastic glioma and pleomorphic glioblastoma, exhibit an aggressive clinical behavior with a poor prognosis, compared with low-grade gliomas. A comprehensive treatment strategy, including a combination of surgery, radiotherapy and chemotherapy is considered optimal in glioma management (3). Although major advances have been made in glioma treatment over the past few decades, the overall survival rate of patients with glioma remains poor and the results of treatment aimed at the prolonged disease-free survival of patients with glioma remain disappointing (4). Since the malignant behavior of glioma cells can be attributed to their inherent genetic abnormalities, it is essential to better understand the underlying molecular mechanisms in order to develop new and effective treatment strategies for this fatal disease.

Temozolomide (TMZ), a 3-methyl derivative of mitozolomide that can easily pass through the blood-brain-barrier, is the commonly used alkylating chemotherapeutic agent in the 
treatment of glioblastoma. The results of phase 2 and 3 clinical trials have confirmed the antitumor activity, with relatively low toxicity, of TMZ in patietns with glioblastoma. However, even though several studies have revealed the apoptotic and anti-proliferative effects of TMZ on glioma cells (5-9), the mechanisms of action of TMZ in glioma cells remain largely undefined. Despite it's the succss of TMZ as a chemotherapeutic agent, gliomas exhibiting resistance to TMZ are common. It has been indicated that the sensitivity of glioma cells to TMZ depends on the intracellular level of $\mathrm{O}^{6}$-methylguanine-DNA methyltransferase (MGMT) repair activity (6).

Members of the sex determining region Y (SRY)-box protein (SOX) gene family are distinguished by a conservative high mobility group DNA-binding domain (10). It has been reported that several SOX genes, including SOX2, SOX4, SOX5, SOX6, SOX10, SOX11, SOX14 and SOX21 are expressed in the central nervous system as transcription factors, and are also involved in brain tumorigenesis (11). The SOX9 variant of the SOX gene family was first found as an important regulator of cartilage and male gonadal development, the mutations in which lead to autosomal sex reversal and campomelic dysplasia $(12,13)$. As an oncogene, the upregulation of SOX9 has been observed in several types of tumors, such as lung cancer $(14,15)$, breast cancer (16), colorectal cancer (17), ovarian cancer (18) and prostate cancer (19). Recently, SOX9 was identified as an oncogene in glioma, the overexpression of which was found to be closely associated with a poor clinical outcome of patients with glioma (20). Despite this reported oncogenic role of SOX9 in glioma, its mechanisms of action, including the regulated downstream molecular signaling pathways, have not yet been completely delineated $(20,21)$. The chemotherapeutic resistance of glioma to TMZ is not regulated by a single signal pathway or molecule, but by a complex molecular network. We thus hypothesized that SOX9 may be an important node in such a molecular network, participating in the development and progression of glioma, and in this study, we assessed its effects on the sensitivity of glioma to TMZ, under in vitro conditions.

\section{Materials and methods}

Reagents. TMZ (purity, 99.95\%) and U-104 (purity, 99.05\%) was obtained from Selleckchem Co., Ltd. (Houston, TX, USA). 4',6-Diamidino-2-phenylindole (DAPI) and 3,8-diamino-5-[3-(diethylmethylammonio)propyl]-6-phenylphenanthridinium diiodide (PI) were obtained from Genview Co., Ltd. (Beijing, China). The following items were purchased from the cited commercial sources: Anti-carbonic anhydrase IX (ab15086), anti-SOX9 (ab26414), anti-BCL-2 (ab32124) and anti-BAX (ab32503) (both from Abcam, Cambridge, MA, USA), anti-AKT (\#9272), phospho-AKT (Ser473; \#4060), $\beta$-actin (8H10D10; \#3700) (all from Cell Signaling Technology, Beverly, MA, USA), goat anti-rabbit IgG (H+L) HRP (BS13278) and goat anti-mouse IgG (H+L) HRP (BS12478) antibodies (both from Bioworld Technology (St. Louis Park, MN, USA).

Cell lines. The human glioma cell lines U251 (astrocytoma), U87 (glioblastoma; as regards this cell line, please also see the Discussion) and 293T cells were obtained from the Chinese Academy of Sciences Cell Bank, Shanghai, China. All cell lines were cultured in Dulbecco's modified Eagle's medium (DMEM) supplemented with $10 \%$ fetal bovine serum (FBS) (Gibco, Calrsbad, CA USA), and incubated at $37^{\circ} \mathrm{C}$ in a humidified atmosphere containing $5 \% \mathrm{CO}_{2}$. Both cell lines were routinely subcultured twice a week by trypsinization, following standard procedures.

Construction of stable cell lines. SOX9 expression was knocked down in the glioma cell lines by shRNA lentivirus infection, using the following target sequences: negative control (NC), TTCTCCGAACGTGTCACGT; SOX9 KD1, GCATCCTTCAATTTCTGTATA; and SOX9 KD2, CTCCA CCTTCACCTACATGAA. pGMLV-SC2 (Genomeditech Co., Shanghai, China) was used as the lentiviral vector. The pGMLV-SC2 negative control and pGMLV-SC2-SOX9 shRNAs were transfected into $293 \mathrm{~T}$ cells to produce the lentivirus, using HG transgene reagent (Genomeditech Co.). The medium containing the $\mathrm{HG}$ transgene reagent was then removed and replaced with fresh medium after $6 \mathrm{~h}$. The lentivirus was added to the U251 and U87 cells. Stable cell lines were selected by culturing the infected U251 and U87 cells in puromycin for 14 days. The expression of SOX9 was confirmed by reverse transcription-quantitative PCR (RT-qPCR) and western blot analysis.

Western blot analysis. Protein analysis was performed using western blot analysis. The cells were lysed in RIPA + PMSF lysis buffer, and the resulting total protein concentration was determined using the Bicinchoninic Acid (BCA) Protein assay kit (Beyotime Biotechnology Corporation, Shanghai, China). An equal amount of protein samples were separated by $10 \%$ SDS-polyacrylamide gel electrophoresis and transferred onto polyvinylidene difluoride (PVDF) membranes. After being blocked with $5 \%$ fat-free milk at room temperature for $2 \mathrm{~h}$, the PVDF membranes were incubated overnight with the primary antibodies (anhydrase IX, SOX9, BCL-2, AKT and phospho-AKT: 1:1,000, BAX: 1:2,000) at $4^{\circ} \mathrm{C}$. Subsequently, the PVDF membranes were incubated with the secondary antibodies (goat anti-rabbit IgG (H+L) HRP (BS13278) and goat anti-mouse $\operatorname{IgG}(\mathrm{H}+\mathrm{L}) \mathrm{HRP}(\mathrm{BS} 12478)$ antibodies: 1:2,000) for $2 \mathrm{~h}$ at room temperature. The membranes were then prepared for enhanced chemiluminescence (ECL), viewed directly under an enhanced chemiluminescence detection system (ChemiDocXRS; Bio-Rad, Hercules, CA, USA), and quantified by densitometry using Image-Pro plus 6.0 (IPP 6.0) software.

$R T-q P C R$. The mRNA expression of the concerned genes was assessed by RT-qPCR. The cells were subcultured into 6-well plates until they were grown to confluence, and then incubated with TMZ $(200 \mu \mathrm{M})$ or U-104 (CA9 inhibitor; $100 \mu \mathrm{M})$ at determined concentrations. Post-incubation, total RNA was extracted from the cells using Total RNA Extraction Reagent (SunShineBio, Nanjing, China) and the cDNA was synthesized with the TransScript First-stand cDNA Synthesis Super Mix (TransGen Biotech, Beijing, China). Subsequently, quantitative PCR was implemented using $20 \mu \mathrm{l}$ of SsoFast ${ }^{\mathrm{TM}}$ EvaGree Supermix (Bio-Rad). PCR reagents were used according to the manufacturer's instructions. The Bio-Rad iQ5 Real-Time PCR system (Bio-Rad) was used to amplify with the following scheme: Initial activation step for $10 \mathrm{~min}$ at $95^{\circ} \mathrm{C}$, followed by 
Table I. List of the top 10 downregulated genes and the top 10 upregulated genes following SOX9 knockdown.

\begin{tabular}{lccc}
\hline Probe set ID & {$[($ SOX9-1) vs. $(\mathrm{NC})$ fold change $\geq 1.5]$} & Regulation [(SOX9-1) vs. (NC) & Gene symbol \\
\hline TC09000191.hg.1 & -190.23251 & Down & CA9 \\
TC12001718.hg.1 & -57.696537 & Down & PTPRB \\
TC12001420.hg.1 & -27.711525 & Down & RNY5 \\
TC04002931.hg.1 & -24.433125 & Down & PDGFRA \\
TC12001366.hg.1 & -19.318275 & Down & AK4P3 \\
TC01002884.hg.1 & -18.039902 & Down & ARHGAP29 \\
TC08001062.hg.1 & -16.57504 & Down & STC1 \\
TC01003040.hg.1 & -15.059714 & Down & SPAG17 \\
TC05001577.hg.1 & -13.410678 & Down & MIR9-2 \\
TC02001031.hg.1 & -13.375226 & Down & PDK1 \\
TC1600535.hg.1 & 23.395475 & $\mathrm{Up}$ & TMEM208 \\
TC11002392.hg.1 & 16.466776 & $\mathrm{Up}$ & SNORD14D \\
TC14000491.hg.1 & 12.988753 & $\mathrm{Up}$ & AHSA1 \\
TC01004004.hg.1 & 10.898638 & $\mathrm{Up}$ & ERO1LB \\
TC01001173.hg.1 & 9.65654 & $\mathrm{Up}$ & HIST2H4B \\
TC03001474.hg.1 & 8.374862 & $\mathrm{Up}$ & SELK \\
TC10000331.hg.1 & 7.95951 & $\mathrm{Up}$ & FAM21D \\
TC12000189.hg.1 & 7.489741 & $\mathrm{Up}$ & EMP1 \\
TC03001014.hg.1 & 7.4074697 & $\mathrm{Up}$ & LOC344887 \\
TC03002706.hg.1 & 7.384494 & $\mathrm{Up}$ & ID4 \\
\hline
\end{tabular}

40 cycles of denaturation for $30 \mathrm{sec}$ at $95^{\circ} \mathrm{C}$ and $10 \mathrm{sec}$ at $60^{\circ} \mathrm{C}$. Primer sequences used are as follows: GAPDH forward, 5'-GAAGGTGAAGGTCGGAGTC-3' and reverse, 5'-GAAG ATGGTGATGGGATTTC-3'; SOX9 forward, 5'-AGGTGCT CAAAGGCTACGACT-3' and reverse, 5'-AGATGTGCGTC TGCTCCGTG-3'; BAX forward,5'-ACACCT GAGCTGACCT TGGA-3' and reverse, 5'-CCGTGTCCACGTCAGCAATC-3'; BCL-2 forward, 5'-AAGCTGTCACAGAGGGGCTA-3' and reverse, 5'-GACGGTAGCGACGAGAGAAG-3'; CA9 forward, 5'-TTTGCCAGAGTTGACGAGGC-3' and reverse, 5'-GCTC ATAGGCACTGTTTTCTTCC-3'. The mRNA level of each gene, normalized and presented as a ratio to GAPDH, was calculated using the $\Delta \Delta$ Cq method (22).

PI/DAPI staining of glioma cells. The cells in the exponential phase, seeded at $2 \times 10^{4}$ cells per well in a 48 -well plate, were grown to near confluency, and were then treated with TMZ $(200$ or $400 \mu \mathrm{M})$ or $\mathrm{U}-104(100 \mu \mathrm{M})$. Apoptosis was detected with a two-color analysis, DAPI binding and PI uptake, as follows: The cells were washed in PBS and incubated with $500 \mu 1$ of DMEM containing $5 \mu 1$ DAPI and $5 \mu 1 \mathrm{PI}$, at $37^{\circ} \mathrm{C}$ temperature for $20 \mathrm{~min}$. The cells were then observed under an inverted fluorescence microscope (Nikon Eclipse Ti; Nikon, Tokyo, Japan), with appropriate filters in the dark. The fluorescence intensity was excited at $488 \mathrm{~nm}$, and the emission was detected at $530 \mathrm{~nm}$. The degree of fluorescence was quantifided by the optical density measurement using Image-Pro Plus 6.0 (IPP 6.0) software.

Microarray and bioinformatics analyses. Total RNA from the cells, extracted using TRIzol reagent (Invitrogen), was labeled and hybridized onto the Agilent One-Color Microarray-Based
Gene Expression Analysis platform (Shanghai Oebiotech Co., Ltd., Shanghai, China). Statistical analyses were performed using the Genespring GX software (Agilent Technologies). Changes in gene expression with a 2-fold change were considered differentially regulated by SOX9. The differentially expressed genes obtained from the gene chip results were uploaded into STRING (http://string-db.org/) to analyze the protein-protein interaction (PPI).

Statistical analysis. All data are expressed as the means \pm SD. Data analysis was performed using the Student's t-test or one-way ANOVA, followed by Newman-Keuls test. The differences were considered statistically significant at $\mathrm{P}<0.05$.

\section{Results}

Lentivirus mediated SOX9 knockdown reduces CA9 expression in glioma cells. SOX9 expression in the U87 and U251 glioma cell lines was effectively knocked down through lentivirus infection with shRNA (Fig. 1A and B), and stable cell lines were established through puromycin-based selection. Both shRNA sequences, referred to as SOX9KD1 and SOX9KD2, were found to be equally effective at knocking down SOX9 in the U87 cell line. Thus SOX9KD1 sequence alone was used in the assessments of U251 cell line. The microarray-based gene expression analysis was performed to analyze the SOX9 downstream target genes in these cells, with the negative control shRNA-infected cells serving as the control. The results revealed that, in response to SOX9 downregulation, the CA9 gene not only topped the list of the top 10 downregulated genes, but also topped the list of all the SOX9-mediated differentially regulated genes (Table I 
A

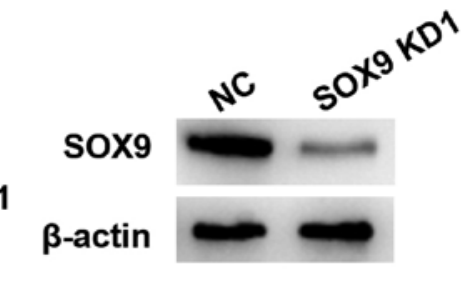

SOX9/ß-actin

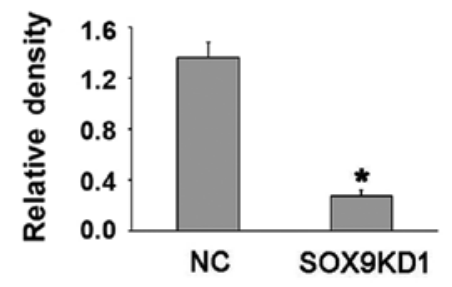

C

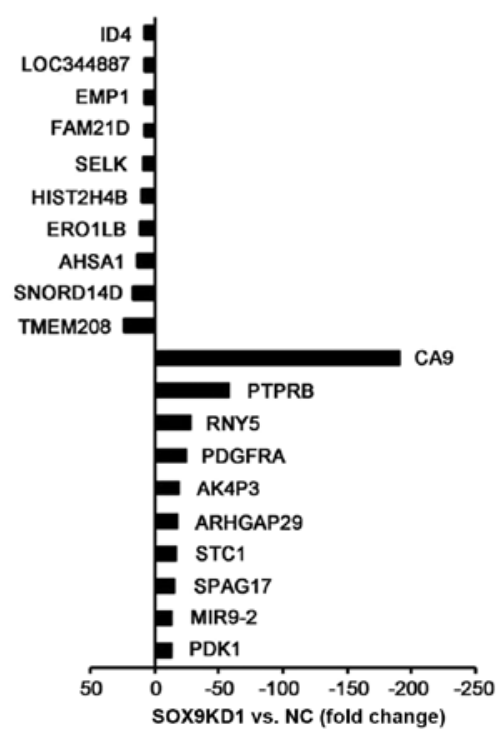

E

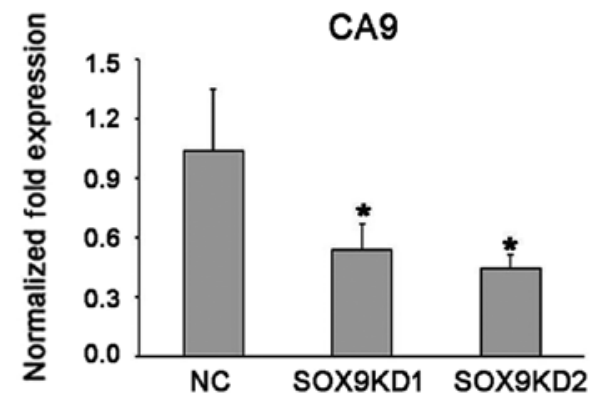

B

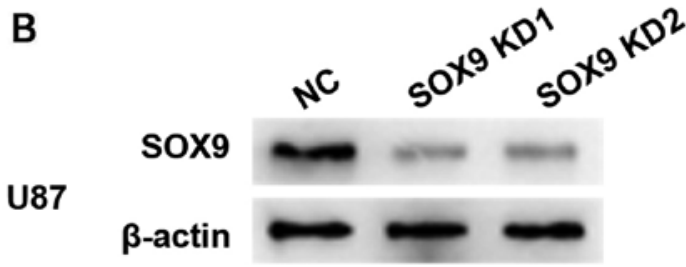

SOX9/ $\beta$-actin

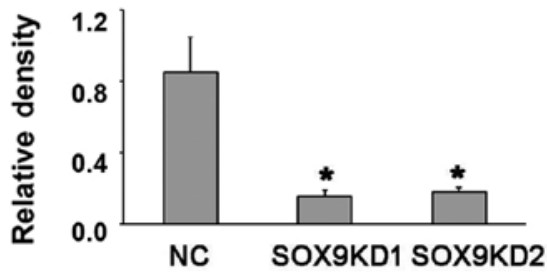

D

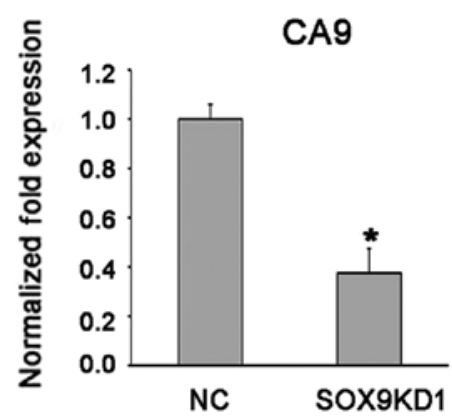

Figure 1. Knockdown of SOX9 inhibits CA9 expression. (A and B) SOX9 protein expression levels were significantly downregulated when SOX9 was knocked down in the U251 and U87 cells. (C) The expression of CA9 was the highest among the first 10 genes upregulated and downregulated, determined by gene expression difference analysis. (D and E) RT-qPCR detected the mRNA levels of CA9 in U251 and U87 cells infected with shRNA lentivirus. "P<0.05 vs. the NC group.

and Fig. 1C). In order to further validate the results, we assessed the mRNA expression of CA9 in the infected U87 and U251 cells, by RT-qPCR, which revealed a significant inhibition of CA9 expression after the silencing of SOX9 (Fig. 1D and E).

Furthermore, PPI networks were constructed with the differentially expressed genes obtained from the gene chip results (Fig. 2). In the network, SOX9 was found strongly associated with CA9, and together they constructed a combined network of downstream survival and apoptotic signals.

SOX9 knockdown enhances the chemosensitivity of glioma cells to TMZ. The role of the SOX9 gene in the sensitivity of U87 and U251 cells to TMZ was examined by incubating the U87 and U251 cells in which SOX9 was knocked down (SOX9KD), and the negative control shRNA-infected cells (NC), with various concentrations of TMZ (200 and 


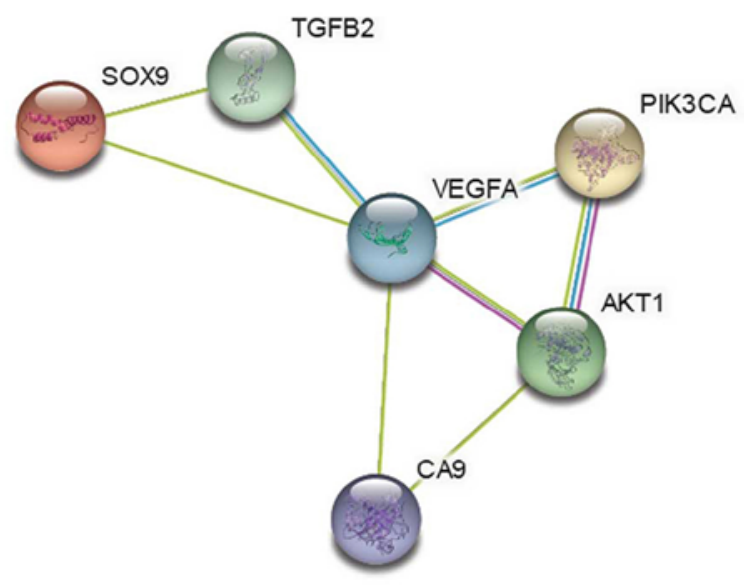

Nodes:

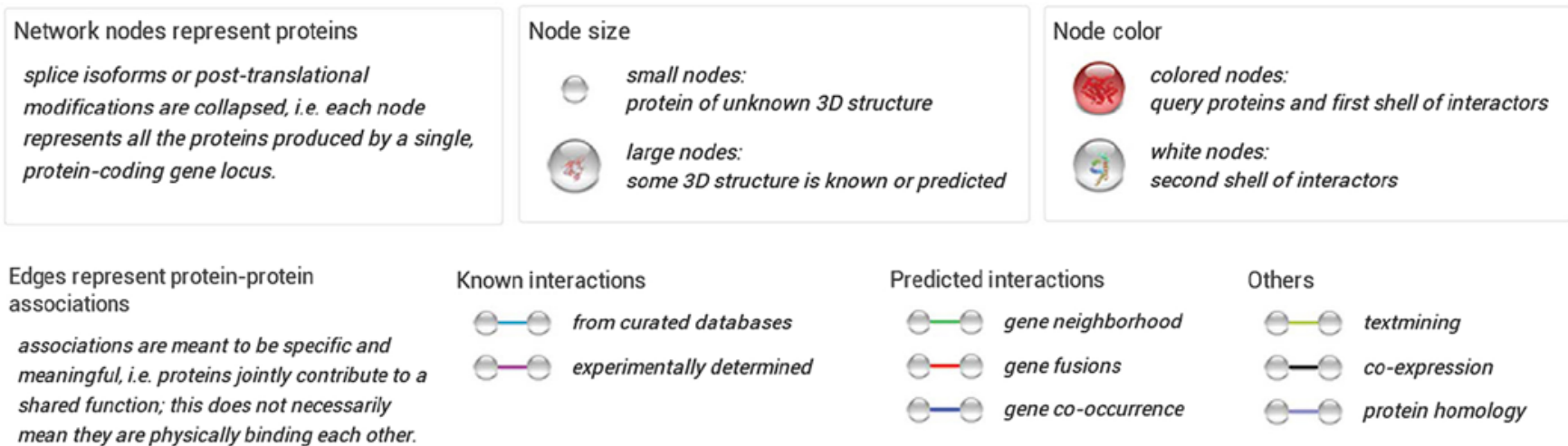

Figure 2. Potential pharmacological channels in the treatment of glioma are shown by protein-protein interaction (PPI). SOX9/CA9 constructed a combined network with downstream survival and apoptotic signals. Note that SOX9 was associated with CA9. The graph suggested that CA9 may be a viable ion channel to be involved in resistance to temozolomide (TMZ).

$400 \mu \mathrm{M})$ for $24 \mathrm{~h}$. Under a light microscope, the number of U251 and U87 cells per field of vision appeared lower in the SOX9KD group, compared to the negative control shRNA-infected glioma cells (Fig. 3A and C), revealing the importance of SOX9 in glioma. In the presence of TMZ, both cell lines exhibited morphological changes (rounding of the cells) and a more obvious growth arrest, which was directly proportional to the TMZ concentration used (Fig. 3A and C). This effect was markedly enhanced in the SOX9KD group compared with the negative control cells. PI staining based on the two-color analysis technique, under a fluorescent microscope, revealed an increased death of glioma cells in response to SOX9 downregulation, compared to the negative control cells. Furthermore, a significant increase in cellular apoptosis was evident in response to TMZ treatment, in both cell lines, which was significantly increased by SOX9 downregulation (Fig. 3B and D). The response was directly proportional to the concentration of TMZ used. These results indicate the involvement of SOX9 in the sensitivity of glioma cells to TMZ.

Inhibitory effect of TMZ on glioma cells: Its mechanisms of action. The mechanisms underlying the inhibitory effects of TMZ on U87 and U251 glioma cell growth wereevaluated by assessing the related survival molecules in the TMZ-treated glioma cells by western blot analysis and RT-qPCR. After exposing the glioma cells to TMZ $(200 \mu \mathrm{M})$ for $16 \mathrm{~h}$, the expression of SOX9 was found to be significantly down- regulated in both the U87 and U251 cells (Fig. 4A and B). Of note, TMZ was equally efficient in further decreasing SOX9 expression in the glioma cells in which SOX9 was silenced (SOX9KD group) (Fig. 4A and B). Considering the association between SOX9 and CA9, we also examined the effect of TMZ on CA9 expression in glioma cells. The results revealed that TMZ significantly downregulated CA9 expression in the glioma cells, with the effect being more significant in the cells in the SOX9KD group (Figs. 5A and $\mathrm{B}$, and $6 \mathrm{~A}$ and $\mathrm{B}$ ). These results demonstrated the inhibitory effects of TMZ on SOX9 and CA9 protein expression in glioma cells. Moreover, TMZ also significantly decreased Akt phosphorylation, in cells in both the negative control and SOX9KD groups, although the change in the expression of Akt remained insignificant (Figs. 5A and $\mathrm{C}$, and 6A and $\mathrm{C}$ ). Based on these findings, we predicted that TMZ may interact with SOX9 and vary the downstream signaling pathway by the direct or indirect effect of SOX9 on CA9. By employing RT-qPCR, we further examined the effects of TMZ on the apoptosis regulatory proteins, BCL-2/BAX, in glioma cells. The results revealed that TMZ effectively inhibited BCL-2 mRNA expression, while upregulating BAX expression in both cell lines, with an enhanced effect observed in the cells in which SOX9 was knocked down (Figs. 4A and B, 5D and $\mathrm{E}$, and $6 \mathrm{D}$ and $\mathrm{E}$ ). These results indicate the possible involvement of SOX9 in the chemosensitivity of glioma cells to TMZ. 
A

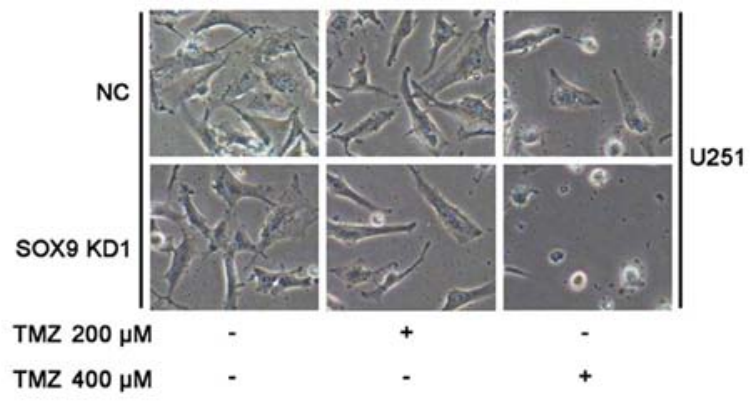

B
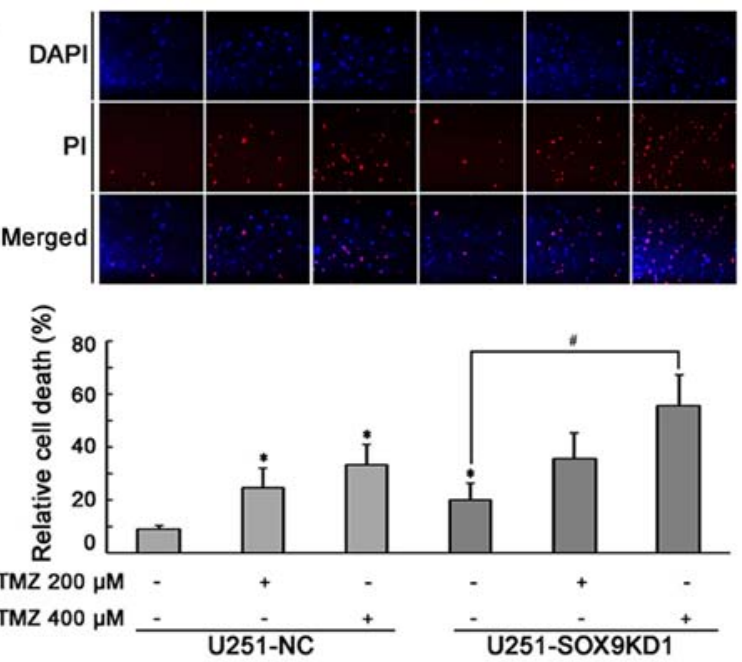

C
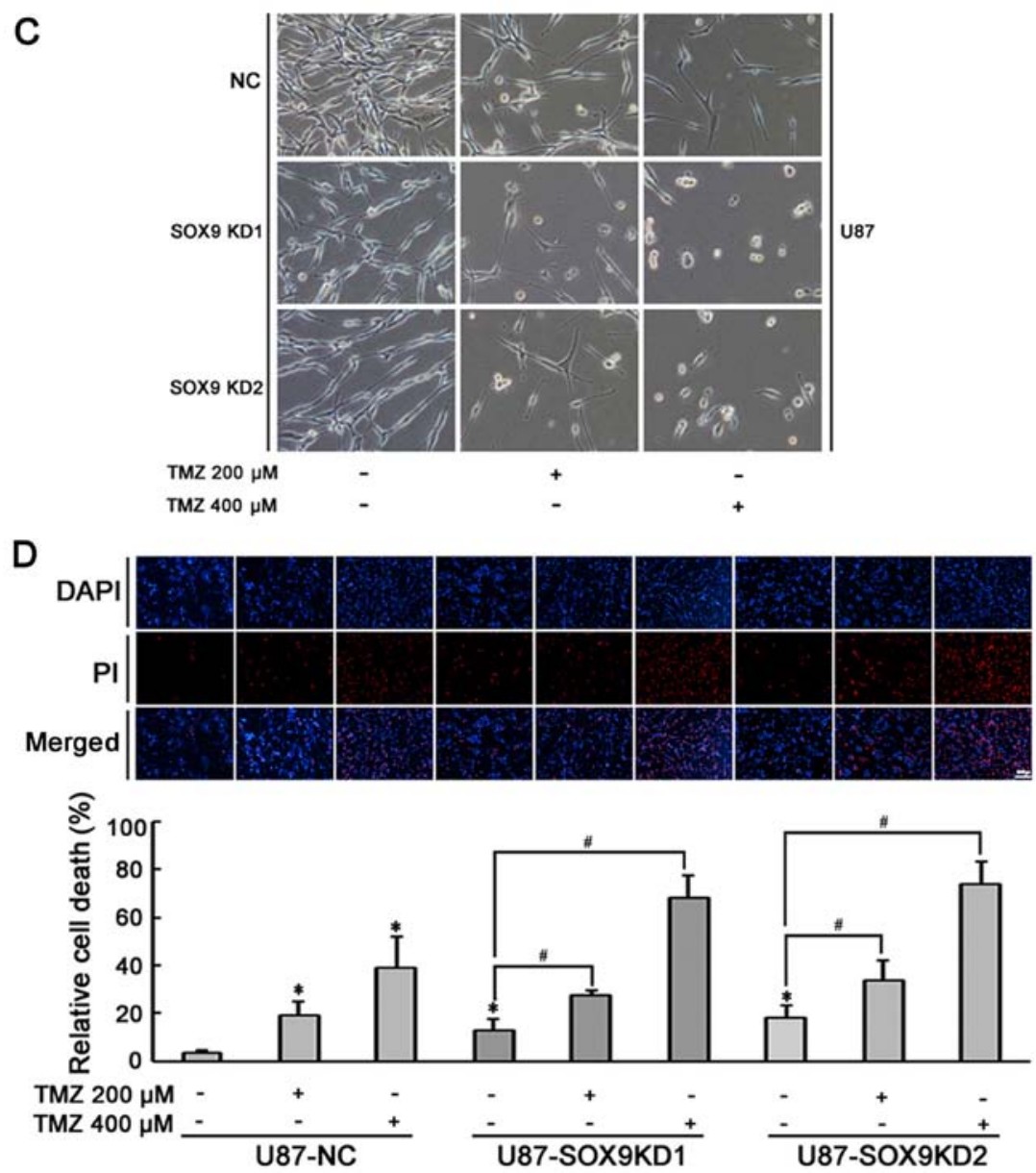

Figure 3. SOX9 knockdown enhances sensitivity to temozolomide (TMZ) in glioma cells. (A and C) Growth arrest and morphological changes in U251 and U87 cells, following treatment with various concentrations of TMZ. (B and D) Cell death assay of U251 and U87 cells in which SOX9 was knocked down, following TMZ treatment, as assessed by PI staining. Data are expressed as the means \pm SD from 4 independent experiments. ${ }^{*} \mathrm{P}<0.05$ vs. the NC group, ${ }^{\#} \mathrm{P}<0.05$ vs. the indicated treatment. 
A
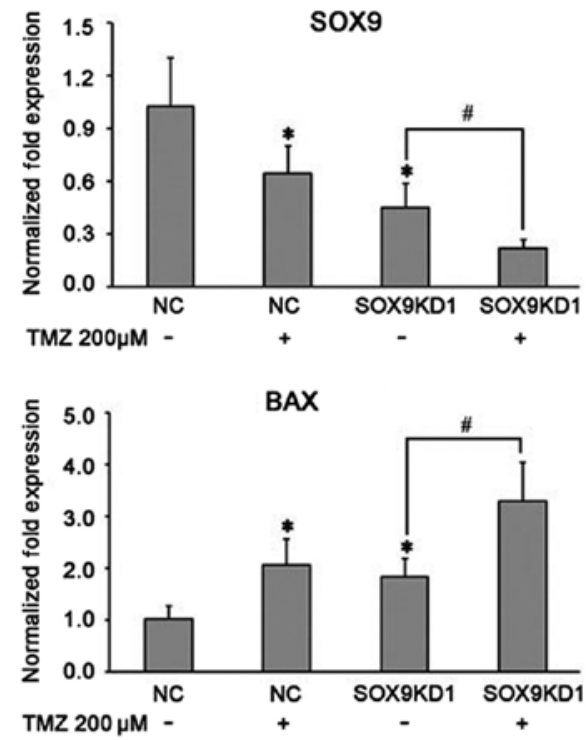

B

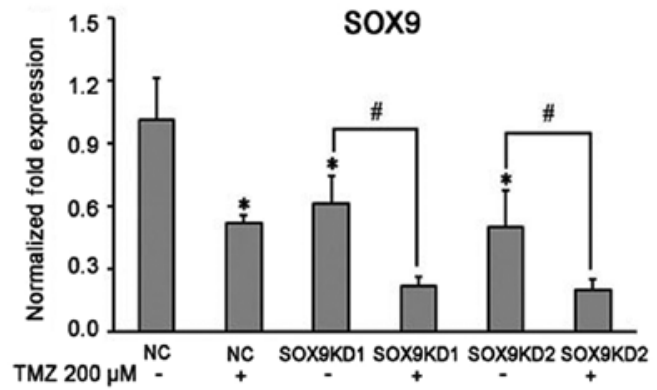

BAX

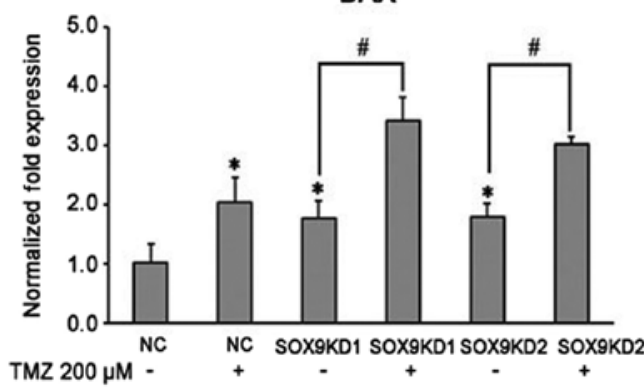

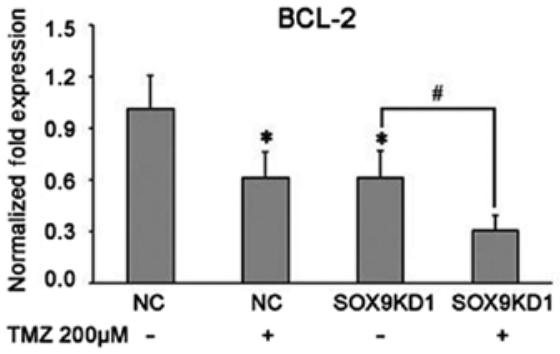

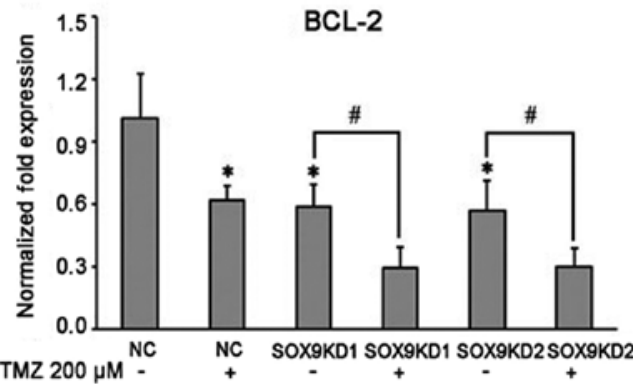

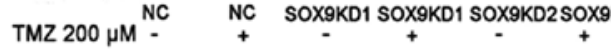

Figure 4. Effect of temozolomide (TMZ) on SOX9 expression and apoptotic signaling molecules following SOX9 knockdown. (A and B) TMZ decreased the mRNA expression of SOX9 and BCL-2, whereas it increasd BAX expression in the U 251 and U87 cells, respectively. " $\mathrm{P}<0.05$ vs. the NC group. ${ }^{*} \mathrm{P}<0.05$ vs. the indicated treatment.

CA9 inhibitor enhances the pro-apoptotic effects of TMZ on U87 and U251 cells. In view of the above-mentioned results, we hypothesized that CA9 expression may also be involved in cellular resistance to TMZ. To examine this hypothesis, we treated the glioma cells with TMZ (200 and $400 \mu \mathrm{M})$ in the presence of CA9 inhibitor (U-104; $100 \mu \mathrm{M}$ ) for $24 \mathrm{~h}$. Under a light microscope, fewer cells per field of vision, with an increased number of cells with an altered morphology, as well cell bodies that had become smaller and rounded as a result of cytoplasmic retraction, were observed in the U-104 + TMZ group, compared to the TMZ alone group (Fig. 7A and $\mathrm{C}$ ). Consistently, PI staining revealed a significant increase in the number of apoptotic cells in the U-104 + TMZ group compared to the TMZ alone group (Fig. 7B and D). The effect was directly proportional to the concentration of TMZ used.
These results suggest that CA9 may also be involved in the chemosensitivity of glioma cells to TMZ.

Synergistic effect of TMZ and CA9 inhibitor (U-104) on glioma cell apoptosis: Mechanisms of action. To examine the role of CA9 inhibition in TMZ-mediated glioma cell apoptosis, the associated survival pathway genes were assessed. The results revealed that, synchronous with the decrease in CA9 expression, the TMZ + U-104 combination substantially decreased SOX9 expression in the glioma cells, compared to the TMZ alone group (Figs. 8A-C, 9A-C, and 10A and B). Furthermore, TMZ + U-104 markedly suppressed the phosphorylation of Akt (Figs. 8D and 9D), while also significantly altering the BCL-2 and BAX expression levels in the glioma cells (Figs. 8E and F, 9E and F, and 10A and B). 

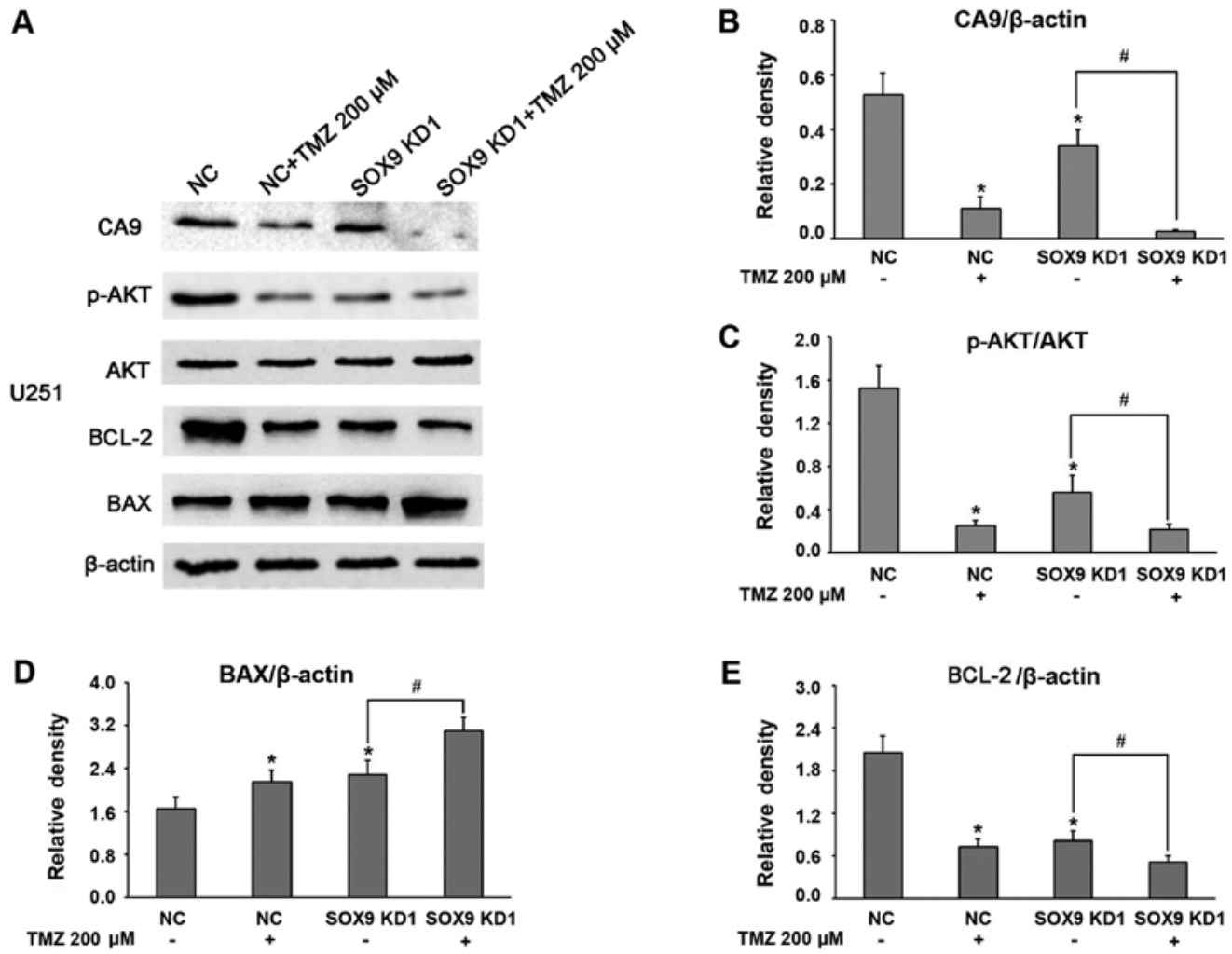

Figure 5. Temozolomide (TMZ) inhibits the expression of CA9, AKT phosphorylation and BCL-2, and promotes BAX expression following SOX9 knockdown in U251 glioma cells. (A-D) Western blot analysis revealed that TMZ treatment inhibited the expression of CA9, p-AKT and BCL-2 in the U251 cells. (E) TMZ treatment promoted BAX expression. Of note, these inhibitory and promoting effects were more significant following SOX 9 knockdown. ${ }^{*} \mathrm{P}<0.05$ vs. the NC group. ${ }^{~} \mathrm{P}<0.05$ vs. the indicated treatment.

A

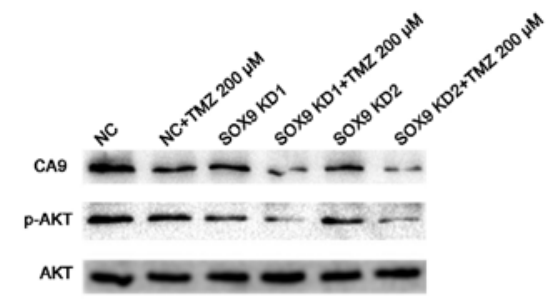

U87
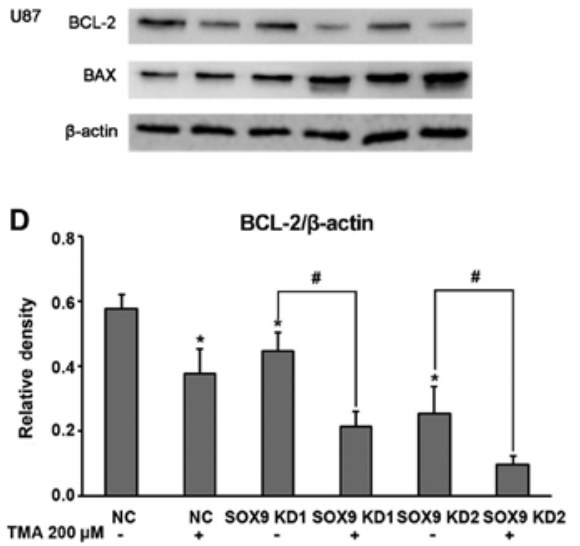
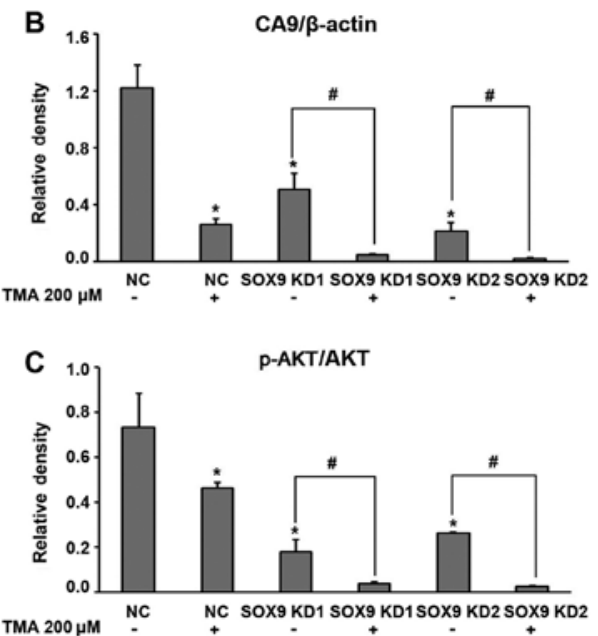

E

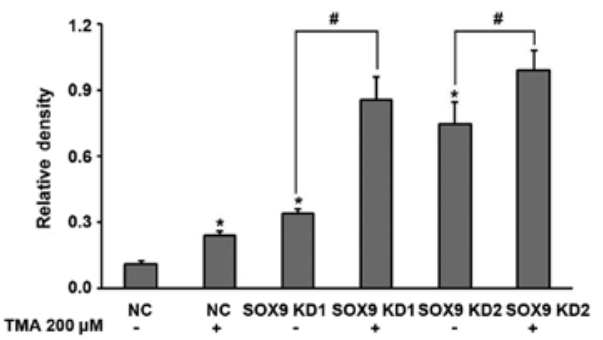

Figure 6. Temozolomide (TMZ) inhibits the expression of CA9, AKT phosphorylation and BCL-2 expression, and promotes BAX expression following SOX9 knockdown in U87 glioma cells. (A-D) Western blot analysis revealed that TMZ treatment inhibited the expression of CA9, p-AKT and BCL-2 in the U87 cells. (E) TMZ treatment promoted BAX expression. Of note, these inhibitory and promoting effects were more significant following SOX 9 knockdown. ${ }^{*} \mathrm{P}<0.05$ vs. the $\mathrm{NC}$ group. ${ }^{\text {}} \mathrm{P}<0.05$ vs. the indicated treatment. 


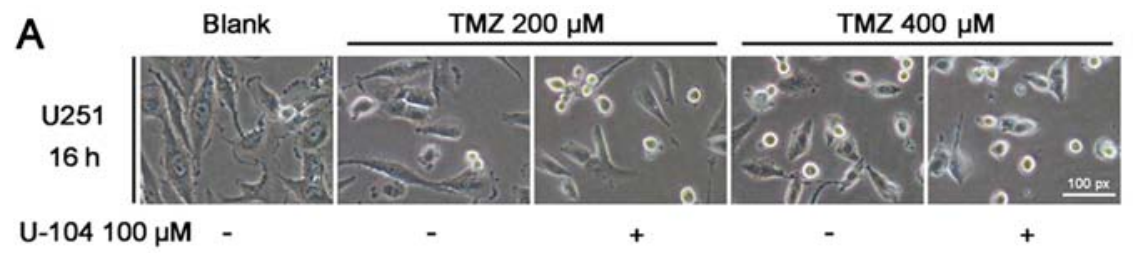

B
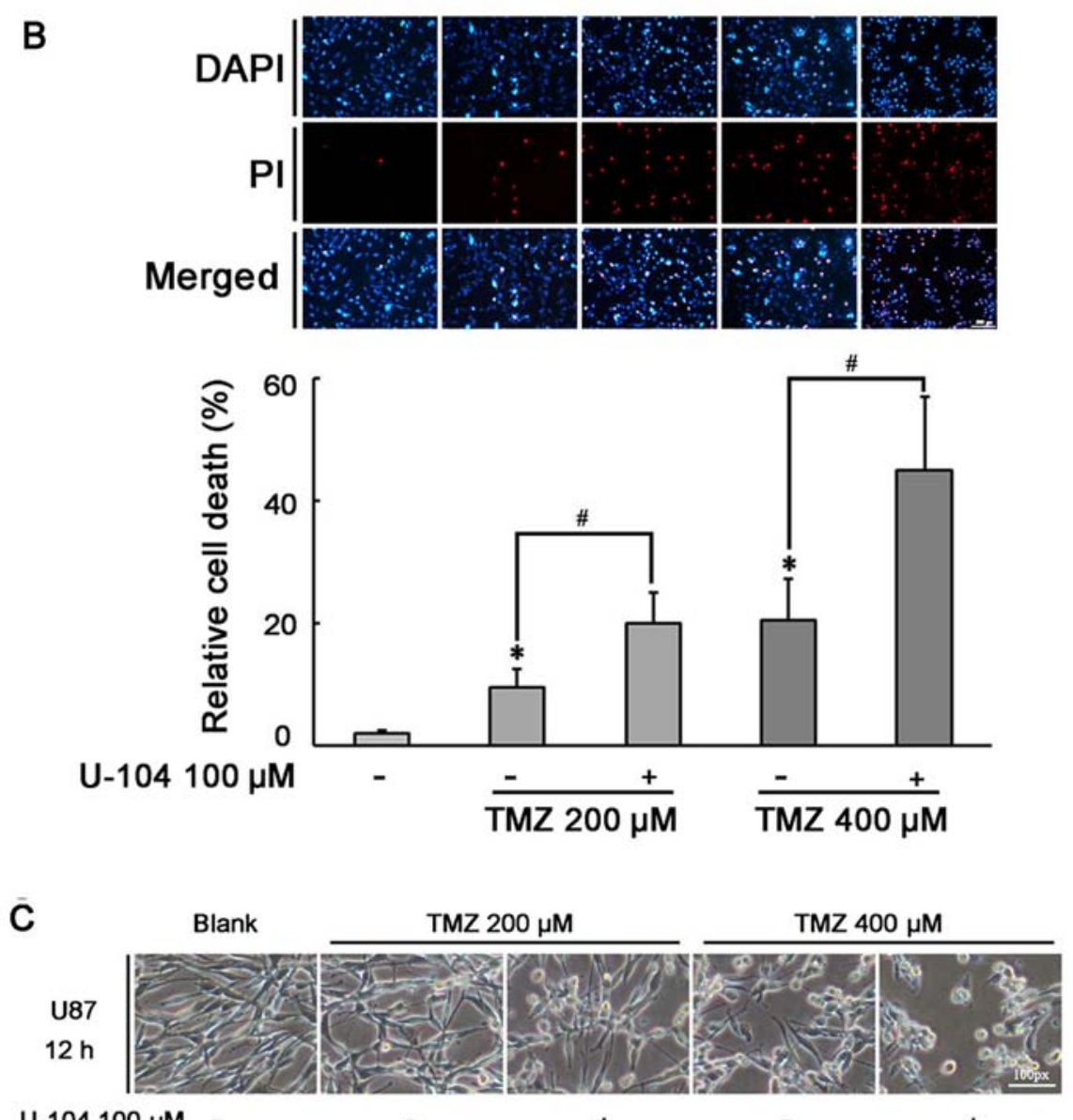

$\mathrm{U}-104100 \mu \mathrm{M}$

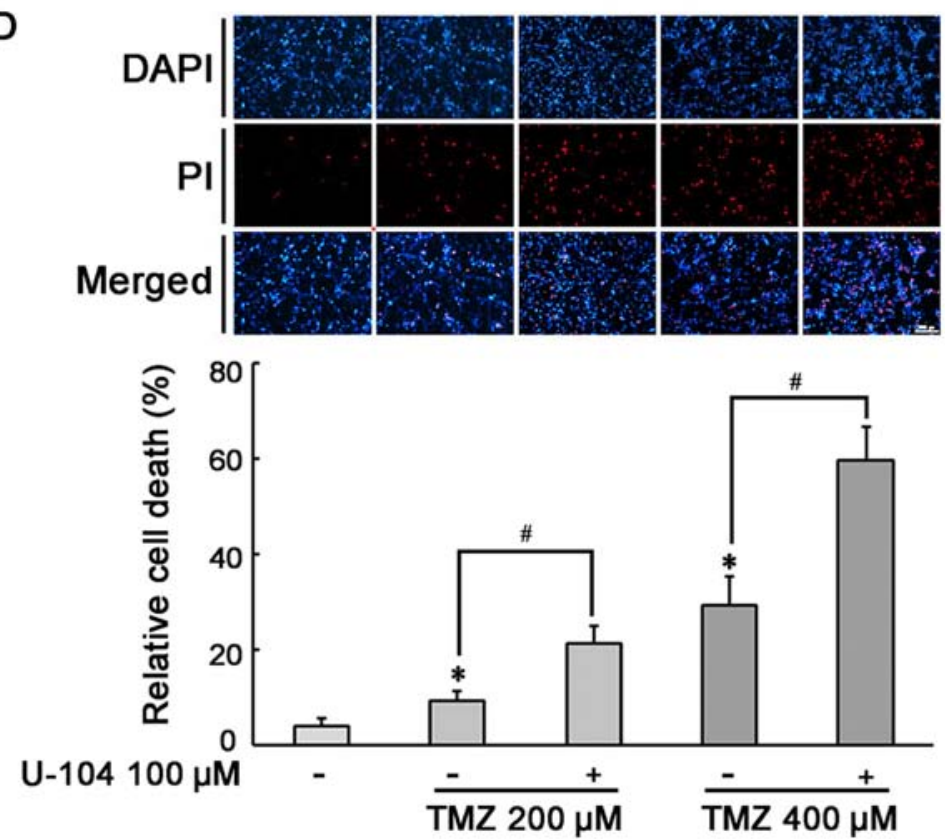

Figure 7. The sensitivity of glioma cells to temozolomide (TMZ) was enhanced when used in combination with CA9 inhibitor. (A and C) CA9 inhibitor (U-104) and TMZ synergistically significantly inhibited cell growth and altered the morphology of the U251 and U87 cells. (B and D) Fluorescence graphs of the cells in early apoptosis (red) following pre-treatment with TMZ alone or TMZ combined with $\mathrm{U}-104 .{ }^{~} \mathrm{P}<0.05$ vs the NC group. ${ }^{~} \mathrm{P}<0.05$ vs the indicated treatment. 
A

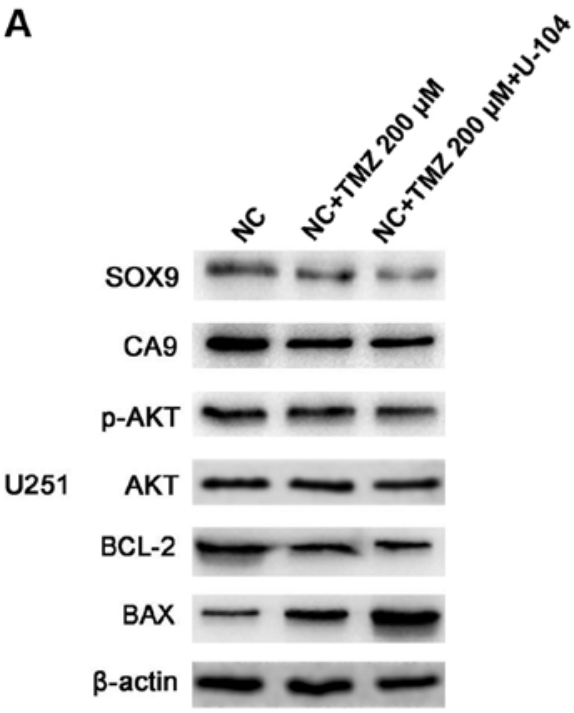

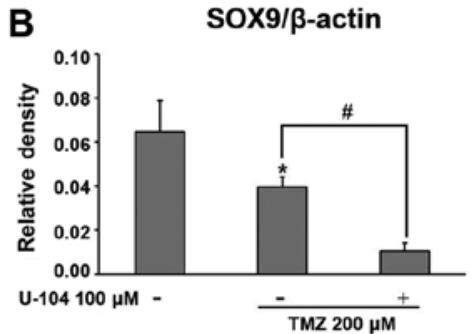

D

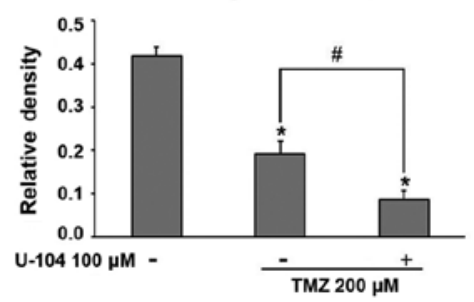

$\mathbf{F}$

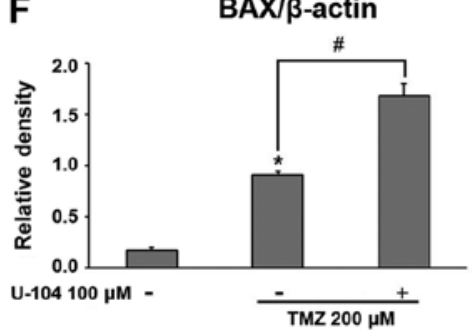

C

CA9/3-actin

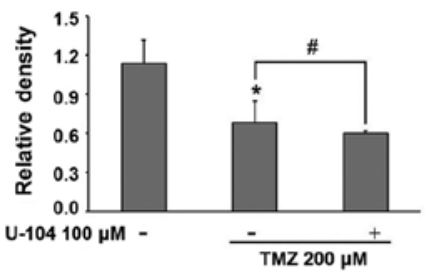

E

BCL-2/ß-actin

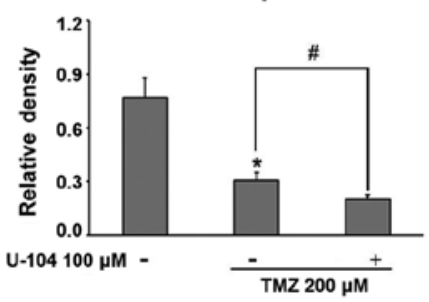

Figure 8. Effect of combination therapy with temozolomide (TMZ) and CA9 inhibitor (U-104) on SOX9/CA9 and apoptotic signaling molecules in U251 glioma cells. (A-E) Synchronous with the decrease in CA9 expression, the TMZ + U-104 combination substantially decreased the expression of SOX9, p-AKT and BCL-2 in glioma cells, and increased the expression of (F) BAX, compared to the TMZ alone group. " $\mathrm{P}<0.05$ vs. the NC group. ${ }^{~} \mathrm{P}<0.05$ vs. the indicated treatment.

A

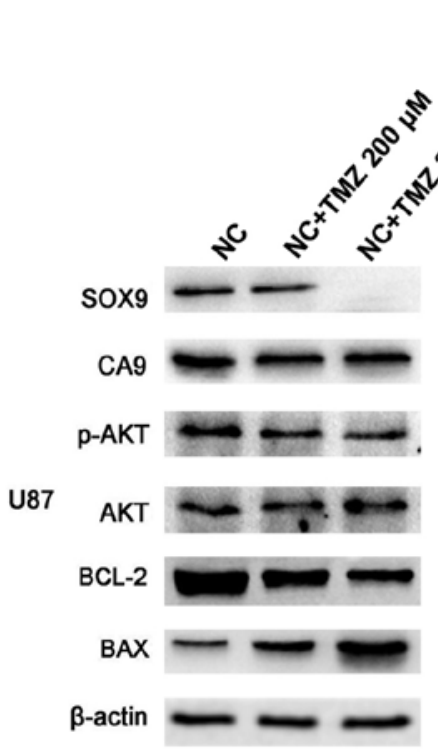

B

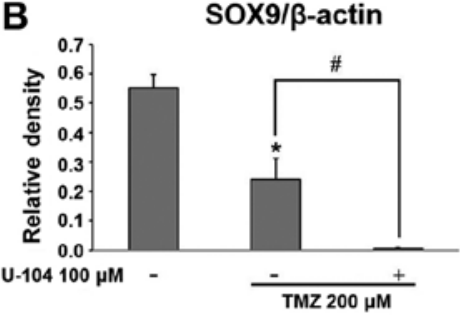

D

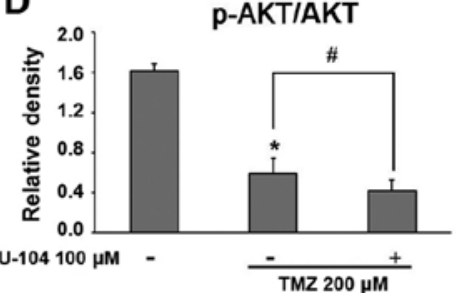

$\mathbf{F}$

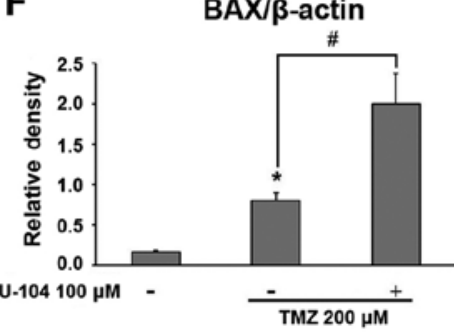

C

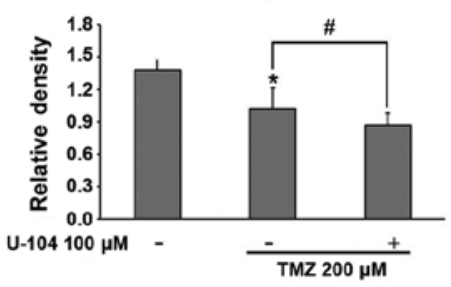

E

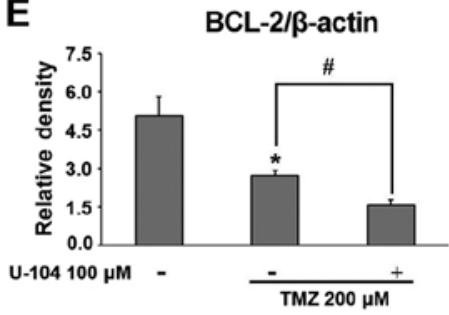

Figure 9. Effect of combination therapy with temozolomide (TMZ) and CA9 inhibitor (U-104) on SOX9/CA9 and apoptotic signaling molecules in U87 glioma cells. (A-E) Synchronous with the decrease in CA9 expression, the TMZ + U-104 combination substantially decreased the expression of SOX9, p-AKT and BCL-2 in glioma cells, and increased the expression of (F) BAX, compared to the TMZ alone group. ${ }^{*} \mathrm{P}<0.05$ vs. the NC group. "P<0.05 vs. the indicated treatment. 

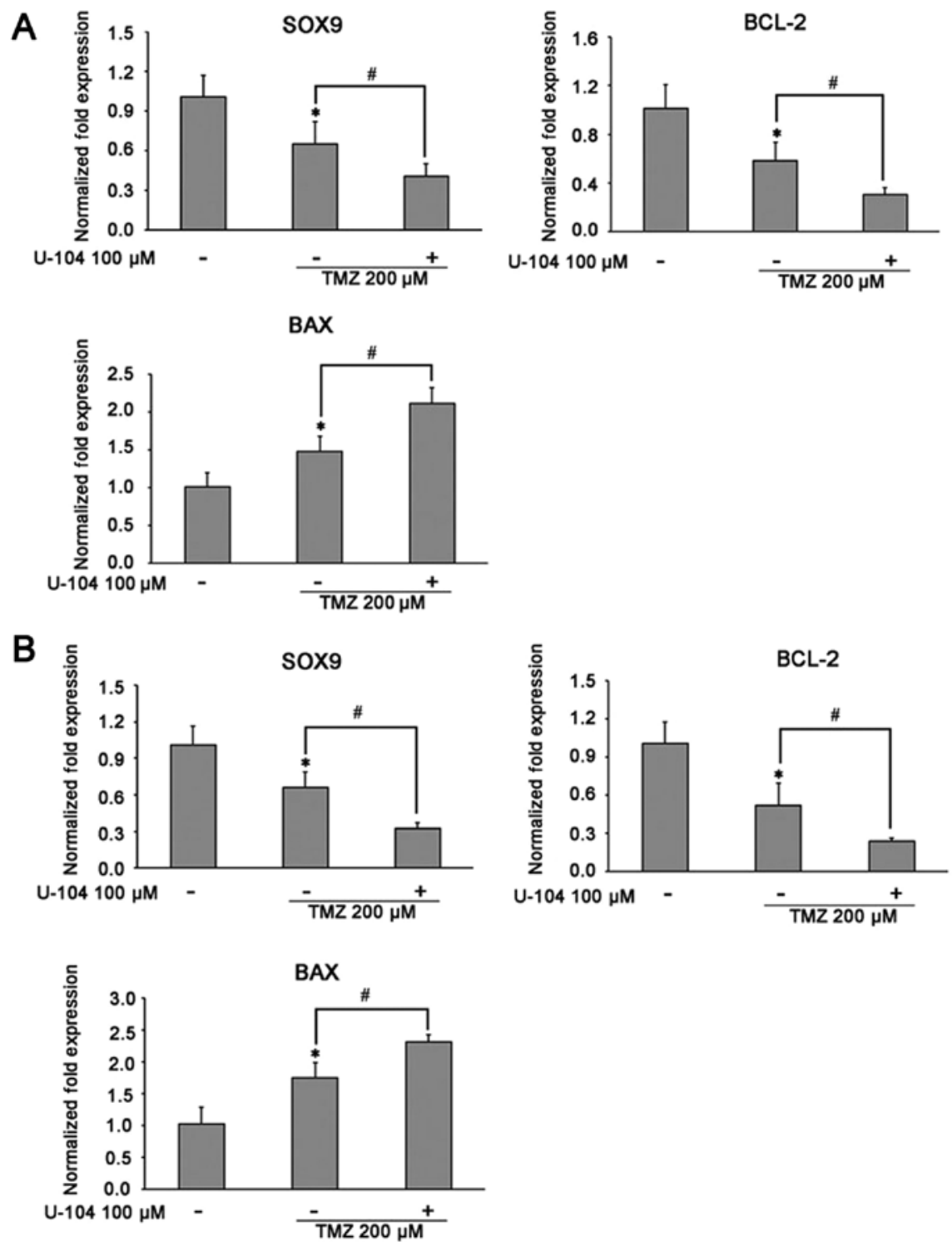

Figure 10. Effect of temozolomide (TMZ) and CA9 inhibitor (U-104) combination therapy on SOX9 expression and apoptotic signaling molecules in U251 and U87 glioma cells. (A and B) TMZ decreased the mRNA expression of SOX9 and BCL-2, whereas it increased BAX expression in the U251 and U87 cells, respectively. ${ }^{*} \mathrm{P}<0.05$ vs. the $\mathrm{NC}$ group. ${ }^{*} \mathrm{P}<0.05$ vs. the indicated treatment.

\section{Discussion}

It has previously been demonstrated that SOX9 plays a key role in the regulation of cellular proliferation and senescence, and in the self-renewal of cancer stem cells, thus supporting tumor development in various types of cancer, including brain tumors, colorectal cancer and prostate cancer $(17,23,24)$. Notably, the inhibition of SOX9 expression has been shown to decrease tumor cell proliferation (25) and to suppress the self-renewal ability of the cells (26), subsequently resulting in tumor regression. Several studies have witnessed the increased expression of SOX9 in glioblastoma (20), the decreased expression of which is linked to a better prognosis by inducing cell cycle arrest in glioma cells $(20,27)$. The fndings of this study also demonstrated that SOX9 inhibition induced the apoptosis of U251 and U87 glioma cells. It has been reported that SOX9 can be regulated by multiple signaling pathways, including EGFR (28), Notch (29), Wnt (30) and hypoxia (31).
Moreover, SOX9 can in turn regulate several pathways, such as Wnt (32), BMI1 (17), PI3K/Akt $(21,33)$. Due to the important role of these signaling pathways in maintaining the stemness of glioma stem cells and the modulation of their chemoresistance, we hypothesized that SOX9 may also play an important role in the regulation of drug resistance in glioma.

TMZ is currently the most efficient chemotherapy for GBM. Indeed, TMZ combined-radiotherapy treatment has been shown to extend the overall survival rate of patients from approximately 3 to $12 \%$ at 4 years compared to treatment with radiotherapy alone (34). TMZ inhibits glioma cell proliferation and migration, and promotes apoptosis (35). The expression levels of SOX9, CA9 and p-AKT are closely related to the proliferation, migration and apoptosis of various tumors (36-38). In this study, we found that TMZ alone can effectively inhibited the expression of SOX9, CA9 and p-AKT (Figs. 8A-D and 9A-D). It has been demonstrated that TMZ enhances the effects of radiotherapy in a randomized phase 
III study (34). However, the damage to glioma cells induced by $\mathrm{TMZ}$ can be repaired by $\mathrm{O}^{6}$-methylguanine-DNA methyltransferase (MGMT), thus inducing treatment resistance, while the methylation of the MGMT promoter leads to an increase in TMZ sensitivity (39). Of note, the U251 and U87 glioma cell lines used in our experiments exhibited MGMT promoter hypermethylation status (40). The findings of this study revealed that the glioma cells exhibited high levels of SOX9 expression, and were less sensitive to TMZ treatment compared to the cells in which SOX9 was silenced. This increase in sensitivity was significant, demonstrating the key role of SOX9 in TMZ sensitivity. Given that SOX9 can be postulated to be one of the key term responsible for resistance to current GBM chemotherapy. Therefore, targeting the activity of SOX9 may provide a novel and promising therapeutic strategy for glioma.

A previous in vitro study examined the role of SOX9 in the apoptosis of human glioma cells (20). However, the mechanism of SOX9-mediated TMZ-induced cell death has not yet been adequately understood. As is known, apoptosis is regulated by several protein families, including the upstream BCL-2 family (e.g., the anti-apoptotic BCL-2 and pro-apoptotic BAX) and the downstream caspase family (e.g., caspase-3) $(41,42)$. Previous studies have demonstrated that treatment with TMZ alters the expression of pro-apoptotic BAX and anti-apoptotic BCL-2, which are involved in the mitochondrial pathway of apoptosis $(43,44)$. It has been demonstrated that the knockdown of SOX9 suppresses cell growth in vitro by affecting the level of apoptosis-related molecules, including the expression of BCL-2 and BAX (45). Thus, in this study, we examined the levels of Bax and Bcl-2 protein expression in U251 and U87 cells in which SOX9 was knocked down following treatmet with TMZ. The results demonstrated a significant increase in BAX expression and a decrease in BCL-2 expression, in the cells in which SOX9 was knocked down compared to the normal glioma cells, in response to TMZ treatment. This indicated an efficient and promoting effect of SOX9 knockdown on the TMZ-mediated regulation of the $\mathrm{BAX} / \mathrm{BCL}-2$ ratio.

In the present study, we found that genomes regulating cell proliferation and cell cycle progression, such as AHSA1 (46), EMP1 (47), ID4 (48) and PDGFRA (49) (shown in Table I), were markedly altered in the cells in which SOX9 was knocked down. The results also revealed that the downregulation of SOX9 suppressed the growth of glioma cells through the CA9-AKT pathway. Thus, a close association was established between SOX9 and CA9, which was also demonstrated by a PPI network. It has been shown that this regulation occurs at the post-transcriptional level and that there is a feedback loop between the two. The proteoglycan domain of CA9 has previously been linked to negative regulation of cell adhesion through the modulation of $\beta$-catenin and E-cadherin interactions (50), whereas the intracellular domain has been shown to contribute to AKT activation (51). CA9 knockdown has shown to reduce the growth rate of tumor xenografts, as reported in two recent studies $(37,52)$. In this study, we identified that SOX9 and CA9 expression were linked together in glioma cells and that the oncogenic activity of SOX9 is at least partially mediated by the latter. Moreover, the decreased levels of CA9 observed in the U251 and U87 cells in which SOX9 was knocked down suggest that SOX9 may be involved in the regulation of glioma.

In an effort to identify the molecules that may efficiently inhibit the expression of SOX9 (direct or indirectly), we found that, in the U251 and U87 glioma cells, the CA9 inhibitor significantly decreased SOX9 expression along with the subsequent cascade of AKT signaling, demonstrating that the pharmacological silencing of SOX9 is feasible using inhibitors of these signaling pathways. Furthermore, a significant alteration in the apoptosis-associated molecules, namely BCL-2 downregulation and BAX upregulation, was also observed in these glioma cells in which CA9 was inhibited. It is vital to note that PI3K pathways are aberrantly active in a high percentage of glioblastomas (53), which may indicate that their action may be modulated through CA9 and SOX9.

An increasing amount of evidence indicates that combining drugs with chemotherapeutic agents is a more effective therapeutic option in cancer. The findings of the present study identified that the concomitant treatment with a CA9 inhibitor (U-104) and TMZ led to a further decrease in AKT phosphorylation, the downregulation of BCL-2 and upregulation of BAX levels, all of which were significant enough to exert a greater cytotoxic effect on the glioma cells, compared to the cells treated with TMZ alone. This suggests that the addition of U-104 to TMZ treatment may potentially enhance the efficacy of TMZ therapy against human glioma.

Currently, there is little information about the association between SOX9 and CA9 in the regulation of glioma drug resistance. Of note, the results of this study confirm the association between them. The results of this study, together with prior evidence, demonstrate that the assessment of the activity of SOX9/CA9 may be a valuable prognostic and predictive marker in glioma.

Although there are many controversies about the U87 MG cell line, we ensure that the aforementioned misidentification issue of the U87MG cell line from ATCC is unlikely to affect the outcomes of our study. The analysis by Allen et al indicated that the U87MG ATCC cell line is likely to be derived from another patient with glioma (54). That is the reason why it differs from the U87 cell line established by Uppsala University. It has been reported that the U87 MG ATCC line is of central nervous system origin, although its source is unknown (54). Recently, the U87MG cell line from ATCC has still been used in studies on glioma (55-57). In future studies, we will replace the U87MG cell line with other classical cell lines that have been validated in order to further refine our experimental results.

\section{Acknowledgements}

Not applicable.

\section{Funding}

This study was supported by grants from the National Natural Scientifc Foundation of China to YZ (no. 81272419), the National Natural Scientifc Foundation of China to YT (no. 81572983), the Social Development of Technology Research Projects in Shaanxi Province to PZ (no. 2015SF027), the Social Development of Technology Research Projects in 
Shaanxi Province to HL (no. 2016SF191), and the Beijing Key Laboratory of Brain Major Diseases Open Project to YT (2015).

\section{Availability of data and materials}

All data generated or analyzed during this study are included in this published article.

\section{Authors' contributions}

YZ, YT, WJ and YC conceived and designed the majority of the experiments. XX, PZ, XW, HY and HL developed the methodology. XX and ZW performed the majority of the experiments. XX and NL performed the analysis and interpretation of the data. XX, ZW and NL wrote, reviewed and revised the manuscript. YZ and YT supported study supervision. All authors have read and approved the manuscript.

\section{Ethics approval and consent to participate}

Not applicable.

\section{Consent for publication}

Not applicable.

\section{Competing interests}

The authors declare that they have no competing interests.

\section{References}

1. Dunn GP, Rinne ML, Wykosky J, Genovese G, Quayle SN Dunn IF, Agarwalla PK, Chheda MG, Campos B, Wang A, et al: Emerging insights into the molecular and cellular basis of glioblastoma. Genes Dev 26: 756-784, 2012.

2. Radner H, Blümcke I, Reifenberger G and Wiestler OD: The new WHO classification of tumors of the nervous system 2000. Pathology and genetics. Pathologe 23: 260-283, 2002 (In German).

3. Qi J, Yang H, Wang X and Tu Y: The progress in molecular biomarkers of gliomas. Cancer Transl Med 2: 125-129, 2016.

4. Stupp R, Mason WP, van den Bent MJ, Weller M, Fisher B, Taphoorn MJ, Belanger K, Brandes AA, Marosi C, Bogdahn U, et al; European Organisation for Research and Treatment of Cancer Brain Tumor and Radiotherapy Groups; National Cancer Institute of Canada Clinical Trials Group: Radiotherapy plus concomitant and adjuvant temozolomide for glioblastoma. N Engl J Med 352: 987-996, 2005.

5. Athanassiou H, Synodinou M, Maragoudakis E, Paraskevaidis M, Verigos C, Misailidou D, Antonadou D, Saris G, Beroukas K and Karageorgis P: Randomized phase II study of temozolomide and radiotherapy compared with radiotherapy alone in newly diagnosed glioblastoma multiforme. J Clin Oncol 23: 2372-2377, 2005.

6. Nagane M, Kobayashi K, Ohnishi A, Shimizu S and Shiokawa Y: Prognostic significance of O6-methylguanine-DNA methyltransferase protein expression in patients with recurrent glioblastoma treated with temozolomide. Jpn J Clin Oncol 37: 897-906, 2007.

7. Groves MD, Puduvalli VK, Hess KR, Jaeckle KA, Peterson P, Yung WK and Levin VA: Phase II trial of temozolomide plus the matrix metalloproteinase inhibitor, marimastat, in recurrent and progressive glioblastoma multiforme. J Clin Oncol 20: 1383-1388, 2002.

8. Bektas M, Johnson SP, Poe WE, Bigner DD and Friedman HS: A sphingosine kinase inhibitor induces cell death in temozolomide resistant glioblastoma cells. Cancer Chemother Pharmacol 64: 1053-1058, 2009.
9. Bocangel DB, Finkelstein S, Schold SC, Bhakat KK, Mitra S and Kokkinakis DM: Multifaceted resistance of gliomas to temozolomide. Clin Cancer Res 8: 2725-2734, 2002.

10. Gubbay J, Collignon J, Koopman P, Capel B, Economou A, Münsterberg A, Vivian N, Goodfellow P and Lovell-Badge R: A gene mapping to the sex-determining region of the mouse $Y$ chromosome is a member of a novel family of embryonically expressed genes. Nature 346: 245-250, 1990.

11. de la Rocha AM, Sampron N, Alonso MM and Matheu A: Role of SOX family of transcription factors in central nervous system tumors. Am J Cancer Res 4: 312-324, 2014.

12. Wagner T, Wirth J, Meyer J, Zabel B, Held M, Zimmer J, Pasantes J, Bricarelli FD, Keutel J, Hustert E, et al: Autosomal sex reversal and campomelic dysplasia are caused by mutations in and around the SRY-related gene SOX9. Cell 79: 1111-1120, 1994.

13. Foster JW, Dominguez-Steglich MA, Guioli S, Kwok C, Weller PA, Stevanović M, Weissenbach J, Mansour S, Young ID, Goodfellow PN, et al: Campomelic dysplasia and autosomal sex reversal caused by mutations in an SRY-related gene. Nature 372: 525-530, 1994

14. Jiang SS, Fang WT, Hou YH, Huang SF, Yen BL, Chang JL, Li SM, Liu HP, Liu YL, Huang CT, et al: Upregulation of SOX9 in lung adenocarcinoma and its involvement in the regulation of cell growth and tumorigenicity. Clin Cancer Res 16: 4363-4373, 2010.

15. Capaccione KM, Hong X, Morgan KM, Liu W, Bishop JM, Liu L, Markert E, Deen M, Minerowicz C, Bertino JR, et al: Sox 9 mediates Notch1-induced mesenchymal features in lung adenocarcinoma. Oncotarget 5: 3636-3650, 2014

16. Chakravarty G, Rider B and Mondal D: Cytoplasmic compartmentalization of SOX9 abrogates the growth arrest response of breast cancer cells that can be rescued by trichostatin A treatment. Cancer Biol Ther 11: 71-83, 2011.

17. Matheu A, Collado M, Wise C, Manterola L, Cekaite L, Tye AJ, Canamero M, Bujanda L, Schedl A, Cheah KS, et al: Oncogenicity of the developmental transcription factor Sox9. Cancer Res 72: 1301-1315, 2012.

18. Raspaglio G, Petrillo M, Martinelli E, Li Puma DD, Mariani M, De Donato M, Filippetti F, Mozzetti S, Prislei S, Zannoni GF, et al: Sox 9 and Hif- $2 \alpha$ regulate TUBB3 gene expression and affect ovarian cancer aggressiveness. Gene 542: 173-181, 2014.

19. Thomsen MK, Ambroisine L, Wynn S, Cheah KS, Foster CS, Fisher G, Berney DM, Møller H, Reuter VE, Scardino P, et al; Transatlantic Prostate Group: SOX9 elevation in the prostate promotes proliferation and cooperates with PTEN loss to drive tumor formation. Cancer Res 70: 979-987, 2010.

20. Wang L, He S, Yuan J, Mao X, Cao Y,Zong J, Tu Y and Zhang Y: Oncogenic role of SOX9 expression in human malignant glioma. Med Oncol 29: 3484-3490, 2012.

21. Swartling FJ,Ferletta M,Kastemar M, Weiss WA and Westermark B: Cyclic GMP-dependent protein kinase II inhibits cell proliferation, Sox9 expression and Akt phosphorylation in human glioma cell lines. Oncogene 28: 3121-3131, 2009.

22. Livak KJ and Schmittgen TD: Analysis of relative gene expression data using real-time quantitative PCR and the $2(-\Delta \Delta \mathrm{C}(\mathrm{T}))$ Method. Methods 25: 402-408, 2001.

23. Swartling FJ, Savov V, Persson AI, Chen J, Hackett CS Northcott PA, Grimmer MR, Lau J, Chesler L, Perry A, et al: Distinct neural stem cell populations give rise to disparate brain tumors in response to N-MYC. Cancer Cell 21: 601-613, 2012.

24. Wang G, Lunardi A, Zhang J, Chen Z, Ala U, Webster KA, Tay Y, Gonzalez-Billalabeitia E, Egia A, Shaffer DR, et al: Zbtb7a suppresses prostate cancer through repression of a Sox9dependent pathway for cellular senescence bypass and tumor invasion. Nat Genet 45: 739-746, 2013.

25. Zhang YJ, Xu F, Zhang YJ, Li HB, Han JC and Li L: miR-206 inhibits non small cell lung cancer cell proliferation and invasion by targeting SOX9. Int J Clin Exp Med 8: 9107-9113, 2015.

26. Larsimont JC, Youssef KK, Sánchez-Danés A, Sukumaran V, Defrance M, Delatte B, Liagre M, Baatsen P, Marine JC, Lippens S, et al: Sox9 controls self-renewal of oncogene targeted cells and links tumor initiation and invasion. Cell Stem Cell 17: 60-73, 2015.

27. Gao J, Zhang JY, Li YH and Ren F: Decreased expression of SOX9 indicates a better prognosis and inhibits the growth of glioma cells by inducing cell cycle arrest. Int J Clin Exp Pathol 8: 10130-10138, 2015. 
28. Ling S, Chang X, Schultz L, Lee TK, Chaux A, Marchionni L, Netto GJ, Sidransky D and Berman DM: An EGFR-ERK-SOX9 signaling cascade links urothelial development and regeneration to cancer. Cancer Res 71: 3812-3821, 2011.

29. Haller R, Schwanbeck R, Martini S, Bernoth K, Kramer J, Just U and Rohwedel J: Notch1 signaling regulates chondrogenic lineage determination through Sox9 activation. Cell Death Differ 19: 461-469, 2012.

30. Blache P, van de Wetering M, Duluc I, Domon C, Berta P, Freund JN, Clevers H and Jay P: SOX9 is an intestine crypt transcription factor, is regulated by the Wnt pathway, and represses the CDX2 and MUC2 genes. J Cell Biol 166: 37-47, 2004.

31. Lafont JE, Talma S, Hopfgarten C and Murphy CL: Hypoxia promotes the differentiated human articular chondrocyte phenotype through SOX9-dependent and -independent pathways. J Biol Chem 283: 4778-4786, 2008.

32. Bastide P, Darido C, Pannequin J, Kist R, Robine S, MartyDouble C, Bibeau F, Scherer G, Joubert D, Hollande F, et al: Sox 9 regulates cell proliferation and is required for Paneth cell differentiation in the intestinal epithelium. J Cell Biol 178 635-648, 2007.

33. Ikegami D, Akiyama H, Suzuki A, Nakamura T, Nakano T, Yoshikawa $\mathrm{H}$ and Tsumaki N: SOX9 sustains chondrocyte survival and hypertrophy in part through Pik3ca-Akt pathways. Development 138: 1507-1519, 2011.

34. Linz U: Commentary on effects of radiotherapy with concomitant and adjuvant temozolomide versus radiotherapy alone on surviva in glioblastoma in a randomised phase III study: 5-year analysis of the EORTC-NCIC trial (Lancet Oncol. 2009;10: 459-466). Cancer 116: 1844-1846, 2010.

35. Yu XZ, Han GK, Yang WT, Li ZY and Jin F: Effect of temozolomide on cell proliferation and migration ability of glioma TJ905 cells. J Xinxiang Medical University 32: 111-114, 2015.

36. Liu N, Zhang L, Wang Z, Cheng Y, Zhang P, Wang X, Wen W, Yang $\mathrm{H}$, Liu H, Jin W, et al: MicroRNA-101 inhibits proliferation, migration and invasion of human glioblastoma by targeting SOX9. Oncotarget 8: 19244-19254, 2017.

37. Lou Y, McDonald PC, Oloumi A, Chia S, Ostlund C, Ahmadi A, Kyle A, Auf dem Keller U, Leung S, Huntsman D, et al: Targeting tumor hypoxia: Suppression of breast tumor growth and metastasis by novel carbonic anhydrase IX inhibitors. Cancer Res 71: 3364-3376, 2011.

38. Song L, Li D, Gu Y, Wen ZM, Jie J, Zhao D and Peng LP. MicroRNA-126 targeting PIK3R2 inhibits NSCLC A549 cell proliferation, migration, and invasion by regulation of PTEN/ PI3K/AKT pathway. Clin Lung Cancer 17: e65-e75, 2016.

39. Gaspar N, Marshall L, Perryman L, Bax DA, Little SE, Viana-Pereira M, Sharp SY, Vassal G, Pearson AD, Reis RM, et al: MGMT-independent temozolomide resistance in pediatric glioblastoma cells associated with a PI3-kinase-mediated HOX/ stem cell gene signature. Cancer Res 70: 9243-9252, 2010.

40. Pyko IV, Nakada M, Sabit H, Teng L, Furuyama N, Hayashi Y, Kawakami K, Minamoto T, Fedulau AS and Hamada J: Glycogen synthase kinase $3 \beta$ inhibition sensitizes human glioblastoma cells to temozolomide by affecting O6-methylguanine DNA methyltransferase promoter methylation via c-Myc signaling. Carcinogenesis 34: 2206-2217, 2013.

41. Jarskog LF, Selinger ES, Lieberman JA and Gilmore JH: Apoptotic proteins in the temporal cortex in schizophrenia: High Bax/Bcl-2 ratio without caspase-3 activation. Am J Psychiatry 161: 109-115, 2004.
42. Kobayashi T, Masumoto J, Tada T, Nomiyama T, Hongo K and Nakayama J: Prognostic significance of the immunohistochemical staining of cleaved caspase-3, an activated form of caspase-3, in gliomas. Clin Cancer Res 13: 3868-3874, 2007.

43. Ma J, Murphy M, O'Dwyer PJ, Berman E, Reed K and Gallo JM: Biochemical changes associated with a multidrug-resistant phenotype of a human glioma cell line with temozolomideacquired resistance. Biochem Pharmacol 63: 1219-1228, 2002.

44. Das A, Banik NL, Patel SJ and Ray SK: Dexamethasone protected human glioblastoma U87MG cells from temozolomide induced apoptosis by maintaining Bax:Bcl-2 ratio and preventing proteolytic activities. Mol Cancer 3: 36, 2004.

45. Stoeckl S, Goettl C, Grifka J and Graessel S: In vitro gene knockdown of SOX9 in rat MSC affects Bcl2 expression. Eur J Cell 89 (Suppl. 1): S14, 2010.

46. Shao J, Wang L, Zhong C, Qi R and Li Y: AHSA1 regulates proliferation, apoptosis, migration, and invasion of osteosarcoma. Biomed Pharmacother 77: 45-51, 2016.

47. Sun GG, Wang YD, Cui DW, Cheng YJ and Hu WN: EMP1 regulates caspase-9 and VEGFC expression and suppresses prostate cancer cell proliferation and invasion. Tumour Biol 35: 3455-3462, 2014.

48. Jason CP, Chaudhary J and Evans A: Abstract LB-6: bHLH transcription factor Id4 plays a regulatory role in cell cycle control, apoptosis, and senescence in androgen-insensitive prostate cancer. Cancer Res 70 (Suppl): 321-327, 2010.

49. Chen D, Zuo D, Luan C, Liu M, Na M, Ran L, Sun Y, Persson A, Englund E, Salford LG, et al: Glioma cell proliferation controlled by ERK activity-dependent surface expression of PDGFRA. PLoS One 9: e87281, 2014.

50. Svastová E, Zilka N, Zat'ovicová M, Gibadulinová A, Ciampor F, Pastorek J and Pastoreková S: Carbonic anhydrase IX reduces E-cadherin-mediated adhesion of MDCK cells via interaction with $\beta$-catenin. Exp Cell Res 290: 332-345, 2003.

51. Dorai T, Sawczuk IS, Pastorek J, Wiernik PH and Dutcher JP: The role of carbonic anhydrase IX overexpression in kidney cancer. Eur J Cancer 41: 2935-2947, 2005.

52. Ebos JM, Lee CR and Kerbel RS: Tumor and host-mediated pathways of resistance and disease progression in response to antiangiogenic therapy. Clin Cancer Res 15: 5020-5025, 2009.

53. McLendon R, Friedman A, Bigner D, et al; Cancer Genome Atlas Research Network: Comprehensive genomic characterization defines human glioblastoma genes and core pathways. Nature 455: 1061-1068, 2008.

54. Allen M, Bjerke M, Edlund H, Nelander S and Westermark B: Origin of the U87MG glioma cell line: Good news and bad news. Sci Transl Med 8: 354re3, 2016.

55. Franco DG, Moretti IF and Marie SK: Abstract 1498: Melatonin inhibits mitochondrial transcription factor A expression in glioblastoma U87MG cell culture inducing an anti-tumorigenic effect. Cancer Res 77 (Supplement): 1498, 2017.

56. Lan YL, Wang X, Xing JS, Yu ZL, Lou JC, Ma XC and Zhang B: Anti-cancer effects of dopamine in human glioma: Involvement of mitochondrial apoptotic and anti-inflammatory pathways. Oncotarget 8: 88488-88500, 2017.

57. Han MZ, Xu R, Xu YY, Zhang X, Ni SL, Huang B, Chen AJ, Wei YZ, Wang S, Li WJ, et al: TAGLN2 is a candidate prognostic biomarker promoting tumorigenesis in human gliomas. J Exp Clin Cancer Res 36: 155, 2017. 